\title{
VEHICLE LOCATION MODELS FOR EMERGENCY MEDICAL SERVICES. AN APPLICATION FOR A COLOMBIAN COMPANY
}

\author{
-. Pablo Zapata-Murillo ${ }^{1}$ \\ MARIA G. BALDOQUiN DE LA PEÑA ${ }^{2}$
}

\section{ABSTRACT}

Ambulance location, in a certain area of coverage, is a key element in reducing the waiting time of a potential patient and the initiation a healthcare service in Emergency Medical Services (EMS). The Operations Research area, developing and solving adequate mathematical models, helps to make good decisions in EMS. We propose two variants of a Mixed Integer Linear Programming model for locating heterogeneous fleet vehicles to support different types of services in emergency medical care, taking into account the operational requirements of a health care service company in Colombia. The proposed models do not exactly match any of those found in the literature. The models are solved with Gurobi solver and the modeling language AMPL and they are successfully validated with historical data of the company under study and some estimates based on external sources. These obtained results are compared using an adaptation of the concept of Preparedness taken from the literature for ambulance positioning, as regard to measure the readiness of the system to the expected demand. The new results show that the relevance of each model depends of the prioritization of services and/ or areas that the company considers.

KEYWORDS: Emergency Medical Services, hospital logistics, ambulance location, mathematical models, linear programming.

1 Ingeniero Industrial. Magister en Ingeniera Industrial..

2 Matemática. Doctora en Matemáticas Aplicadas. Profesor Pensionado. Universidad EAFIT, Medellín, Antioquia.

Autor de correspondencia: Zapata-Murillo, P. (Pablo): Calle 10 bis No. 70 - 34, Cali, Valle. Tel.: +57 3154283216. Correo electrónico: pablozapatamur@gmail.com
Historia del artículo:

Artículo recibido: 02-XI-2017 / Aprobado: 20-IV-2017

Disponible online: 3 de mayo 2018

Discusión abierta hasta octubre de 2019 


\section{MODELOS DE LOCALIZACIÓN DE VEHÍCULOS PARA SERVICIOS DE EMERGENCIA MÉDICA. UNA APLICACIÓN PARA UNA COMPAÑÍA COLOMBIANA}

\section{RESUMEN}

La localización de ambulancias, en una determinada área de cobertura, es un elemento clave para reducir el tiempo de espera de un paciente potencial y la iniciación del servicio de atención médica en los Servicios Médicos de Emergencia (EMS). La Investigación de Operaciones, desarrollando y resolviendo modelos matemáticos adecuados, ayuda a tomar buenas decisiones en el EMS. Proponemos dos variantes de un modelo de programación lineal mixta para localizar vehículos de flota heterogénea y apoyar diferentes tipos de servicios en atención médica de emergencias, teniendo en cuenta las necesidades operacionales de una empresa de servicios de salud en Colombia. Los modelos propuestos no coinciden exactamente con ninguno de los encontrados en la literatura. Los modelos se resuelven con el solver Gurobi y el lenguaje de modelado AMPL y son validados con éxito con datos históricos de la empresa en estudio y algunas estimaciones basadas en fuentes externas. Estos resultados se comparan utilizando una adaptación del concepto de Preparednessd de la literatura para la ubicación de ambulancias, en lo que respecta a la disposición del sistema a la demanda esperada. Los nuevos resultados muestran que la relevancia de cada modelo depende de la priorización de servicios y/o áreas que la empresa considere.

PALABRAS CLAVE: Servicios de Emergencia Médica, Logística Hospitalaria, Localización de ambulancias, Modelos Matemáticos, programación lineal.

\section{MODELOS DE LOCALIZAÇÃO DE VEÍCULOS PARA SERVIÇOS MÉDICOS DE EMERGÊNCIA. UM PEDIDO PARA UMA EMPRESA COLOMBIANA}

\section{RESUMO}

A localização da ambulância, em uma certa área de cobertura, é um elemento chave na redução do tempo de espera de um paciente potencial e na iniciação de um serviço de saúde em Serviços Médicos de Emergência (EMS). A área de Pesquisa de Operações, desenvolvendo e resolvendo modelos matemáticos adequados, ajuda a tomar boas decisões no EMS. Propomos duas variantes de um modelo de Programação Linear Inteira Mista para localizar veículos de frotas heterogêneos para suportar diferentes tipos de serviços em atendimento médico de emergência, levando em consideração os requisitos operacionais de uma empresa de serviços de saúde na Colômbia. Os modelos propostos não correspondem exatamente a nenhum dos encontrados na literatura. Os modelos são resolvidos com o solucionador Gurobi e a linguagem de modelagem AMPL e são validados com dados históricos da empresa em estudo e algumas estimativas baseadas em fontes externas. Estes resultados obtidos são comparados usando uma adaptação do conceito de Preparação extraído da literatura para o posicionamento da ambulância, no que se refere à medida da disponibilidade do sistema para a demanda 
esperada. Os novos resultados mostram que a relevância de cada modelo depende da priorização de serviços e / ou áreas que a empresa considere.

PALAVRAS-CHAVE: Serviços médicos de emergência, logística hospitalar, localização da ambulância, modelos matemáticos, programação linear.

\section{INTRODUCTION}

The main goal of Emergency Medical Services (EMS) is to provide an early response to emergency calls from users. The design of EMS systems considers several interconnected strategic decisions, at different levels. These decisions involve adequate location of emergency vehicles. A rich literature exists on vehicle location models for EMS systems, considering different objectives, multiple response time standards, multiple vehicle types, and multiple vehicle response requirements, in both static and dynamic environments. These models usually have two objectives: minimizing the mean response time and maximizing coverage. There are varied definitions of response time and coverage areas. In this paper, response time is considered as the time it takes a vehicle to travel from its location to the area where the service is required (Gendreau et al., 1997, Toro-Díaz et al., 2013); coverage is defined in terms of a radius (time units) within which patients shall be reached, considering that a demand point $i$ is covered by site $j$ if and only if the time between $i$ and $j$ is at most $r$ where $r$ is a preset coverage standard (Gendreau et al., 1997, Schmid and Doerner, 2010).

We present two variants of ambulance location models, considering both heterogeneous fleet (ambulances are of different types and capacities) and different types of service (demand), using two strategies for coverage radius for demand. Although the models take into account the operational requirements of a health care service company in Colombia, they may be extensible to other similar companies with EMS services. The proposed models does not match any of those found in the literature.

There are different modelling approaches, considered to address problems related to ambulances' location arising in EMS (Bélanger et al., 2015, Brotcorne et al., 2003, Goldberg, 2004). In vehicle location problems, coverage critical is often a key consideration though approaches vary substantially. Diverse static ambulance location models can be divided in single coverage deterministic models, multiple coverage deterministic models and probabilistic and stochastic models. Representative single coverage deterministic models are the Location Set Covering Problem (LSCP) (Toregas et al., 1971) and The Maximal Covering Location Problem (MCLP) (Church and ReVelle, 1974). Both LSCP and MCLP consider only one type of vehicle and one type of service. The multiple coverage deterministic models seek to increase the likelihood of having a demand zone covered, with more than one vehicle available to cover the zone. There are some representative models of this type (Daskin and Stern, 1981, Gendreau et al., 1997, Hogan and ReVelle, 1986). The last of the previous models cited (Gendreau et al., 1997) considers both the concept of double coverage and different coverage radii (DSM model); in the second (Hogan and ReVelle, 1986) the BACOP models. Some variants of these models were developed, including new restrictions or objectives; for example, the refined DSM model, adding operational costs in the objective function (Su et al., 2015).

Probabilistic and stochastic models consider more accurate representation of real-life situations. Some representative models in the literature reviewed are: The MEXCLP model, which maximizes the expected coverage with deterministic travel times (Daskin, 1983); models with stochastic travel times (Daskin, 1984, Goldberg et al., 1990), an extension of the MCLP with random travel times (Alsalloum and Rand, 2006), a model with probabilistic constraints to consider more explicitly 
random service requests (Beraldi et al., 2004). All these previous types of models consider only one type of vehicle and one type of service.

Three single coverage deterministic models (Schilling et al., 1979) aim to maximize the population simultaneously covered by two types of vehicles; in (ReVelle and Marianov, 1991) is proposed a probabilistic version of one of the previous models. A covering-type model for twotiered EMS systems was proposed (Mandell, 1998), which incorporates two types of servers with different capabilities and circumstances under which a service call is adequately served given these two types of servers.

Location-allocation approaches have been used to improve efficiency of EMS in Colombia. A study based on the DSM model (Céspedes et al., 2009) was developed to address the problem of location and relocation of ambulances in the city of Bogota. A location model (Villegas et al., 2012) was developed to determine the number of needed vehicles to assist the calls reported to a single number of emergency. This model was based on the MEXCLP model, maximizing population coverage while considering one type of vehicle and one type of service. A methodology, based on Linear Programming and Simulation, was proposed (Ortega et al., 2007) to locate and determine the area of mobility of vehicles in Bogota for the prehospital care sector, with a homogeneous fleet. In the first model (Alsalloum and Rand, 2006) it is considered the 3 types of service of the company, but it is reduced to a homogeneous fleet (simplification that does not agree with the way the company operates); the problem is solved separately for two time slots in the day, considered low and high demand. The second model implemented (Singer and Donoso, 2008) uses queuing theory, and also it considers homogeneous fleet and exclude one of the type of service of the company.

Many of the mentioned models are MultiObjective Optimization Models (MOOP), and different techniques exist to solve them. A MOOP is often solved using a weighted-sum approach. In the weighted-sum method, the optimal solutions depend of the weights assigned to the different objective functions, including normalization factors in some cases. In real applications reviewed is not considered how the weighting factors were obtained.

In ambulance logistics, preparedness has been used since a long time, as a qualitative measure, of evaluating the ability of ambulances to attend potential patients atpresentand in the future, in a swift and efficient manner. This concept can have different meanings, depending on the experience, personality, etc., of the ambulance controllers. New algorithms were formulated for the ambulance dispatch and the dynamic ambulance relocation problems, using a quantitative definition of preparedness (Andersson and Värbrand, 2007). The implementation of the preparedness measure used includes a list of the closest ambulances for each zone, sorted according to the expected travel time. The decision about which ambulance is dispatched depends also of the level of prioritization of the call (in their implementation there are 3 levels of prioritization).

The main contribution of this paper is to formulate some variants of the DSM and mDSM models considering:

- Different types of vehicle and types of service (demand).

- Maximum number of calls of each type of service which can be cover by a vehicle in each period.

- In both models the demand, availability of vehicles and travel times vary over a time horizon, penalizing the number of relocated vehicles between periods. The travel times consider both traffic congestion and type of service.

- A weighted-sum approach in the MultiObjective Optimization Models considered. It is shown, in a real context, how the weighting factors are determined. 
These models take into account the operational requirements of a health care service company in Colombia, and some other elements to give a satisfactory representation of real-life situations, in a tactical level of decision-making. According with the related work exposed, these models have not been considered up to now. Also, a definition of Preparedness is proposed to identify if there are some models better than others, considering maximize the preparedness, according with the definition proposed.

\section{METHODOLOGY}

Currently, the vehicles are located taking into account the experience of planning staff, possible locations and historical demand data according to three parameters: type of service, part of the city that should be covered and different periods of time in the day. This process doesn't guarantee the best decisions. There are some basic assumptions, derived from the features and operational rules of the company object of study.

1. Three types of services are considered: two types of medical emergency (here called emergency and urgency, according to the "degree of urgency") and home visit. The emergency is a situation in which the physical, functional or psychological integrity of the individual may compromise the patient's life, necessitating immediate attention in order to preserve life. Urgency is a situation that presents no risk to the life or integrity of the patient, but that requires prompt attention, to not worsen the condition. In this paper the transfer, a fourth type of service of the company, is not considered.

2. A maximum response time is established for each type of service. The services are ordered in increasing order, according the maximum response time allowed: emergency, urgency, home visit.
3. The fleet has 3 types of vehicles with different capacities care. These capacities refer to the types of services they can attend. The type of vehicle with larger capacity can attend all types of service; the type of vehicle with smaller capacity can attend only one type of service, home visits. The lower-capacity vehicles could provide temporary support to other services, until a suitable vehicle is available.

4. The average time of a vehicle, between its location and the patient location, depends on: the distance between the two places, if the traffic congestion is high or low and the service type. An emergency, or urgency, needs to activate the sirens of ambulances so that travel time is reduced.

5. There are restrictions on the number of vehicles that can be located in a position, both by number as by type of vehicle. At each location point there should be no more than two vehicles and they should be of different types.

6. The company has clustered the city in 5 zones, according to a previous study developed. If a zone is covered by a location, it is assumed that the whole population in this region is covered by this location. However, a new more favorable zoning for the vehicles localization is proposed in the implementation of the models (Section of Computational Experiments).

\subsection{Problem formulation}

In order to consider an acceptable representation of different real situations of our vehicle location problem, in a tactical level of decision-making, we extend the DSM model in several ways:

- $\quad$ One or two coverage standards defined, but each coverage radius differs depending of the type of service.

- Demand variations, availability of vehicles and traffic congestion in different time 
periods is considered, as well as it is avoided or minimized the unnecessary changes in the location of vehicles between two consecutive periods.

- Considerations to handle the probability that a vehicle is unavailable to respond to an emergency call.

The different time periods considered, are defined from 24 periods of one hour each. A period is composed for those consecutive time periods in which the available fleet is identical, and there are not significant differences in service demands and travel times, based on historical traffic congestion. To determine the number of vehicles that can satisfy the demand for each type of service in each area, two factors are considered: the demand for each type of service in the area, and an estimate of the maximum number of calls of each service which can be satisfied by a vehicle in the period considered. The average time of a vehicle, between its location and the patient location, depends on: the distance between the two places, if the traffic congestion is high or low and the service type.

The objective function is a weighted function of two objectives defined: maximize the demand coverage and minimizing the relocation of vehicles between periods. The relative importance of each of the terms of the objective function is defined using the AHP method (Saaty, 2008) and validated with expert judgment of the company staff. A normalization process of the different functions considered should be made, because they have different measurement units.

Two variants of a model are proposed, taking into account the previous considerations. In the Model 1 a fixed time period and two coverage standards are defined. The total demand must be covered by at least an ambulance located within the largest radius of coverage. The total demand covered one time and twice, within the small radius of coverage, is maximized with different weighting factors. The Model 2 only considers a radius of coverage and ensures that all demand is covered at least once, but not necessarily within the radius considered. The objective function differs from Model 1 that it incorporates minimizing the total travel time of the demand not covered in the radius considered.

\subsubsection{Mathematical formulation of} The Model 1

Notations to describe the model:

$I$ : Set of potential vehicle locations, $I=\{1, \ldots, n\}$.

$J$ : Set of demand points (zones), $J=\{1, \ldots, m\}$.

$S$ : Types of service provided by the system, $\mathrm{S}$ $=\{1, \ldots, q\}$.

$K$ : Types of vehicles available in the system to provide services, of different capacities, $K=\{1, \ldots, p\}$.

$K_{s}$ : Types of vehicles that can attend the service $s, s \in S, K_{s} \subseteq K, \forall s \in S$.

According to the current system operating company, $q=p=3, K_{1}=\{1\}, K_{2}=\{1,2\}, K_{3}=\{1,2,3\}$.

$i$ : Index for the potential vehicle sites.

$j$ : Index for demand points.

$k, s$ : Indices for vehicle type and service type, respectively.

$r_{\mathrm{s}}^{1}$ : Maximum time a vehicle may take to cover a service of type $s$ within the r1 time units.

$r_{s}^{2}$ : Maximum time a vehicle may take to cover a service of type $s$ within the $\mathrm{r} 2$ time units, $r_{\mathrm{s}}^{1}<r_{\mathrm{s}}^{2}$.

$u_{i j s}$ : Average time it takes a vehicle from $i$ to $j$ to cover a service of type $s$.

$d_{j s}$ : Demand of the service of type $s$ in zone $j$.

$p_{k}$ : Number of vehicles available of type $k$.

$y_{i k}^{p}$ : Number of vehicles of type $k$, located at $i$ in the previous period.

$\varpi_{s}$ : Maximum number of service calls of type $\mathrm{s}$ which can be cover by a vehicle in the time period considered.

$S_{1}, S_{2}, S_{3}$ : Weights in the objective function.

$n_{1}, n_{1}$ : Normalization factors in the objective function. 
$I_{j \mathrm{~s}}^{1}=\left\{i \in I: u_{i j s} \leq r_{s}^{1}\right\}$ The set of locations $i$ that can cover with radius 1 the service type $s$ in the zone $j$.

$$
I_{j s}^{2}=\left\{i \in I: u_{i j s} \leq r_{s}^{2}\right\} \text { The set of locations } i \text { that can }
$$
cover with radius 2 the service type $s$ in the zone $j$.

\section{Variables:}

$x_{j s}^{1}: 1$ if the type of service s for the zone $j$ is covered by at least one vehicle in the radius 1,0 otherwise.

$x_{j s}^{2}: 1$ if the type of service $\mathrm{s}$ for the zone $j$ is covered by at least two vehicles in the radius 1,0 otherwise.

$A_{k}: 1$ if in this period there is located at least one vehicle of type $k$, but any in the previous period; 0 otherwise.

$y_{i k}$ : Number of vehicles type $k$ located in $i$.

$w_{i k}$ : Number of vehicles of type $k$ relocated in $i$, respect to the previous period.

$E_{i k}$ : Number of vehicles of type $k$ located in $i$, but not in the previous period in nowhere.

$L_{k}$ : Number of vehicles type $k$ that were placed in the previous period and are removed in this period.

\section{The formulation is:}

Maximize $z=s_{1} n_{1} \sum_{j \in J} \sum_{s \in S} d_{j s} x_{j s}^{1}+s_{2} n_{1} \sum_{j \in J} \sum_{s \in S} d_{j s}$

$$
x_{j \mathrm{~s}}^{2}-s_{3} n_{2} \sum_{i \in I} \sum_{k \in K} w_{i k}
$$

subject to:

$$
\begin{array}{cr}
\sum_{i \in I_{j s}^{2}} \sum_{k \in K_{s}} y_{i k} \geq \frac{d_{j s}}{\omega_{s}} & \forall j \in J, \quad s \in S \\
\sum_{i \in I_{j \mathrm{~s}}^{1}} \sum_{k \in K_{s}} y_{i k} \geq x_{j s}^{1}+x_{j s}^{2} & \forall j \in J, \quad s \in S \\
x_{j s}^{1} \geq X_{j s}^{2} & \forall j \in J, \quad s \in S \\
\sum_{i \in I} y_{i k} \leq p_{k} & \forall k \in K
\end{array}
$$

$$
\begin{array}{cr}
y_{i k} \leq 1 & \forall i \in I, \quad k \in K \\
\sum_{k \in\{1,2\}} y_{i k} \leq 1 & \forall i \in I \\
\sum_{k \in\{2,3\}} y_{i k} \leq 1 & \forall i \in I \\
\sum_{k \in\{1,3\}} y_{i k} \leq 2 & \forall i \in I \\
\sum_{i \in I}\left(y_{i k}-y_{i k}^{p}\right)=\left(\sum_{i \in I} E_{i k}\right)-L_{k} & \forall k \in K \\
y_{i k}-y_{i k}^{p} \leq w_{i k}+E_{i k} & \forall i \in I, \quad k \in K \\
\sum_{i \in I} E_{i k} \leq p_{k} A_{k} & \forall k \in K \\
L_{k} \leq\left(1-A_{k}\right) \sum_{i \in I} y_{i k}^{p} & \forall k \in K \\
x_{j s}^{1}, x_{j s}^{2}, A_{k} \in\{0,1\} & \forall j \in J, \quad s \in S \\
y_{i k}, E_{i k}, L_{k}, w_{i k} \in \mathbb{Z}^{+} & \forall i \in I, \quad k \in K
\end{array}
$$

The objective function (1) maximizes the total demand covered in the radius 1 (with simple and double coverage), while penalizing the relocation of vehicles of the previous period to the current. Constraints of type (2) ensure that the number of vehicles located to cover each service type in each area, in the second radius, should be at least the minimum number of vehicles required in each area for that service type. Type restrictions (3) ensure that, for each area and each service type, there must be at least one (two) vehicle (s) to cover the demand at least once (twice), considering the first radius. Type restrictions (4) ensure that a service in an area is covered at least twice only if it is covered at least once. Type restrictions (5) ensure that the total number located of vehicles, of each type, shouldn't exceed the available number. Restrictions of type (6) ensure that each potential location should have at most one vehicle of each type. Constraints of type (7) to (9) impose conditions for the maximum number of vehicles located in each place, taking into account different combinations of types of vehicles considered. 
The restrictions (10) to (13) refer to the entry, exit and relocation of vehicles in the system between two consecutive periods. Type restrictions (10) ensure that the difference between the vehicles placed in this period and those who were placed in the previous period corresponds to the vehicles that are incorporated or ceasing to be used in the current period. The restrictions (11), whatever the type of vehicle and potential location point considered, impose that the number of vehicles that can be added should be at most the number of vehicles relocated in that point, plus the vehicles entering to the system at this point and period. Constraints (12) ensure that the maximum number of vehicles of each type that can enter to the system in the period is the amount available of such vehicles for this period. Constraints (13) ensure that the maximum number of vehicles of each type that can leave the system in this period is equal to the number of such vehicles located in the previous period. Constraints (14) and (15) define the domain of the variables.

\subsection{Mathematical formulation of} The Model 2

Variables, sets and parameters defined in Model 1 are remained, except the parameters related to the second radius of coverage $\left(r_{s}^{2}\right.$ and $\left.I_{j s}^{2}\right)$. This model has two new variables, integer and binary, respectively. Two new weighting and normalization factors in the objective function are necessary, denoted $s_{4}$ and $n_{3}$, respectively. The formulation is:

$z_{i j s}:$ Number of vehicles located in $i$ to cover the demand of service type $s$ of zone $j$, outside the coverage radius considered, 0 otherwise.

$b_{i j s}=1$ if at least a vehicle is located in $i$ to cover the service type $s$ of the zone $j$, outside the coverage radius considered, 0 otherwise.

Maximize $z=s_{1} n_{1} \sum_{j \in J} \sum_{s \in S} d_{j s} x_{j s}^{1}+s_{2} n_{1} \sum_{j \in J} \sum_{s \in S} d_{j s} x_{j s}^{2}-$

$$
s_{3} n_{2} \sum_{i \in I} \sum_{k \in K} w_{i k}-s_{4} n_{3} \sum_{i \in I} \sum_{j \in J} \sum_{s \in S} u_{i j s} b_{i j s}
$$

subject to:

$$
\begin{aligned}
& \sum_{i \in I_{j s}^{1}} \sum_{k \in K_{s}} y_{i k}+\sum_{i \in I} z_{i j s} \geq \frac{d_{j s}}{\omega_{s}} \quad \forall j \in J, \quad s \in S \\
& \sum_{i \in I_{j s}^{1}} \sum_{k \in K_{s}} y_{i k} \geq x_{j s}^{1}+x_{j s}^{2} \quad \forall j \in J, s \in S \\
& x_{j \mathrm{~s}}^{1} \geq x_{j \mathrm{~s}}^{2} \quad \forall j \in J, \quad s \in S \\
& \sum_{k \in K_{s}} y_{i k} \geq Z_{i j s} \quad \forall i \in I, j \in J, \quad s \in S \\
& b_{i j s} \sum_{k \in K_{s}} p_{k} \geq z_{i j s} \quad \forall i \in I, j \in J, \quad s \in S \\
& \sum_{i \in I_{j s}^{1}} b_{i j s} \leq 0 \quad \forall j \in J, s \in S \\
& \sum_{i \in I} y_{i k} \leq p_{k} \quad \forall k \in K \\
& y_{i k} \leq 1 \quad \forall i \in I, \quad k \in K \\
& \sum_{k \in\{1,2\}} y_{i k} \leq 1 \quad \forall i \in I \\
& \sum_{k \in\{2,3\}} y_{i k} \leq 1 \quad \forall i \in I \\
& \sum_{k \in\{1,3\}} y_{i k} \leq 2 \quad \forall i \in I \\
& \sum_{i \in I}\left(y_{i k}-y_{i k}^{p}\right)=\left(\sum_{i \in I} E_{i k}\right)-L_{k} \quad \forall k \in K \\
& y_{i k}-y_{i k}^{p} \leq w_{i k}+E_{i k} \quad \forall i \in I, \quad k \in K \\
& \sum_{i \in I} E_{i k} \leq p_{k} A_{k} \quad \forall k \in K \\
& L_{k} \leq\left(1-A_{k}\right) \sum_{i \in I} y_{i k}^{p} \quad \forall k \in K \\
& x_{j j^{\prime}}^{1} x_{j j^{\prime}}^{2} A_{k^{\prime}} b_{i j s} \in\{0,1\} \quad \forall i \in I, j \in J, k \in K, s \in S \\
& z_{i j j^{\prime}} y_{i k^{\prime}} E_{i k^{\prime}}, L_{k}, w_{i k} \in \mathbb{Z}^{+} \forall i \in I, j \in J, k \in K, s \in S
\end{aligned}
$$

The objective function, in relation to Model 1, only has added the minimization of the total travel time in the satisfaction of the demand not covered

Revista EIA Rev.EIA.Esc.Ing.Antioq/Universidad EIA 
in the radius considered. The constraints of type (17) are equivalent to the restrictions of type (2) in Model 1; only new vehicles are added, those which cover services outside the coverage area considered. Also, the set $\mathrm{I}_{\mathrm{js}}{ }^{2}$ is replaced by $\mathrm{I}_{\mathrm{js}}{ }^{1}$, because the model considers only one radius of coverage. Restrictions (18), (19), (23) to (31) are respectively restrictions (3) to (13) of Model 1.

Constraints (20) - (22), associated with new variables, are new in this model. Constraints (20) limit the number of vehicles to cover a service in an area, outside the coverage radius, from a given location, taking into account the total number of vehicles available. Constraints (21) are logical, which imposes restrictions on the maximum number of vehicles to attend outside the radio coverage only if the related new decision variable takes the value 1 . The restrictions (22) ensure that, for any type of service, and any demand point, the potential vehicle locations to attend that demand point and type of service, in the radius of coverage, will not have vehicles to attend that demand point and type of service, outside of the radius of coverage. Constraints (32) and (33) define the domain of the variables.

\subsection{Normalization and weighting in} the objective functions of the proposed models

The objective functions in the proposed models are weighted functions of some objectives defined. The weightings play an important role in ensuring the consistency of optimal solutions with the preferences expressed by decision makers, when a multi-objective function is transformed to a singleobjective one with the weighted sum method. On the other hand, the normalization of objective functions are required when these functions are represented by various measure units. The proposed models consider various functions with different priorities. Moreover, their values are expressed in different units of measurement, whose ranges of domain are different; for example, demand (expressed in average number of calls) and number of vehicles relocated from one period to other.

The method used to normalize the different terms of the objective function in the proposed models is a variation of a method using the ideal or utopian solution ( $\mathrm{z}^{\text {ideal }}$ ) and Nadir ( $\mathrm{z}^{\text {nadir }}$ ) (Grodzevich and Romanko, 2006). Then, each term is represented on a scale between zero and one or very near to one.

The AHP method is the procedure used to obtain the weighting coefficients s1, s2 and s3 in the objective functions of the proposed models, and is contextualized to the case study. The Analytic Hierarchy Process (AHP) tool (Saaty, 2008) aids to the decision makers to set priorities. Each function of the weighted objective function is considered an alternative for the AHP. The set of evaluation criteria considered are:

- Cost: Refers to the economic costs of relocation of a vehicle or the security risk in each location. One of them is used according to the objectives outlined in the proposed models. For example, for the objective "penalization for relocation" is considered an economic cost, in the case of objectives "simple coverage" and "double coverage" is considered the risk.

- Response time.

- Coverage: Coverage level of demand within range one time.

For Model 1, the three objectives (single coverage, double coverage and the penalization for relocation) are evaluated under the three criteria described. The relocation of vehicles for each period allows flexibility to the system and be adaptable to: changes in expected demand, changes in available fleet and in travel times that may be affected by different traffic conditions during the day in the city. However, the costs can increase by relocating vehicles frequently; for that reason, the penalization for relocation is higher when compared to the other two objectives taking into 
account the criterion of cost. The single coverage seeks to maximize the cover demand at least by a vehicle in the first radius of coverage; then, this objective has greater weight than the relocation under the criterion of response time. The double coverage can produce a high concentration of vehicles in one spot to cover only some areas with high demand, affecting response time and service provision in other areas; for that reason, the simple coverage is preferable when the response time and coverage criterion are considered.

Model 2 include a fourth objective, the penalization of travel times to an area where the demand is out of the radius considered. This penalization favors the response time, however, this goal is not more important than the simple coverage within the radius considered because the models seek first that the demand can be covered within that radius.

In the validation of the models the comparative evaluation of the alternatives, respect to the criteria defined, was made taking into account the opinion of the staff of the company. The final results, after the AHP method was completed, are the weights shown in Table 1.

TABLE 1. WEIGHTING FACTORS IN THE OBJECTIVE FUNCTIONS OF THE MODEL 1 AND MODEL 2

\begin{tabular}{l|c|c|}
\multicolumn{1}{c|}{ Objective } & Model 1 & Model 2 \\
\hline Simple coverage & 0,58 & 0,46 \\
\hline Double coverage & 0,30 & 0,16 \\
\hline Penalization due to relocation & 0,12 & 0,09 \\
\hline $\begin{array}{l}\text { Total travel time for demand } \\
\text { not covered in radius 1 }\end{array}$ & -- & 0,29 \\
Source: Author & & \\
\hline
\end{tabular}

\subsection{Computational experiments}

Fourteen scenarios (instances) were considered for Models 1 and 2, one for each period of a day. The models were programmed in AMPL and the Gurobi solver is used with the tool Neos Server.

Twenty one potential points in the city to locate their vehicles, at any time of day; these points satisfy the security and parking conditions. The demand to each type of service may be significantly different in two areas with different characteristics. For example, there are residential areas with a high number of affiliate where demand for home visits is high. In other areas, where universities and companies are concentrated, there are corporate members who are interested to protect their employees against possible emergencies orurgenciesintheworkday.Emergencies have lower expected demand and represent less than $1 \%$ of the system care. The city communes, which are areas where the city is administratively divided. The centroid for each commune is determined taking into account its geography and the expected demand in their neighborhoods. The possible location points and demand areas, with their centroids, are showed in Figure 1.

It is also considered:

1. Fourteen time periods, constructed from 24 periods of one hour each one, where the data of consecutive periods don't vary (vehicles) or are similar (demand and travel times).

2. Maximum times of displacement of vehicles to cover each service, determined by the company. These times allow defining the two coverage radii for each type of service in order to cover the demand.

3. The first coverage radius corresponds to the compliance times specified by the company for each service. At present these times are fulfilled in a low percentage of calls. The coverage radius 2 should ensure that all demand can be covered in this radio under the current conditions of mobility in the city and the limitations of the company. In Model 2 only is used the coverage radius 1 . 


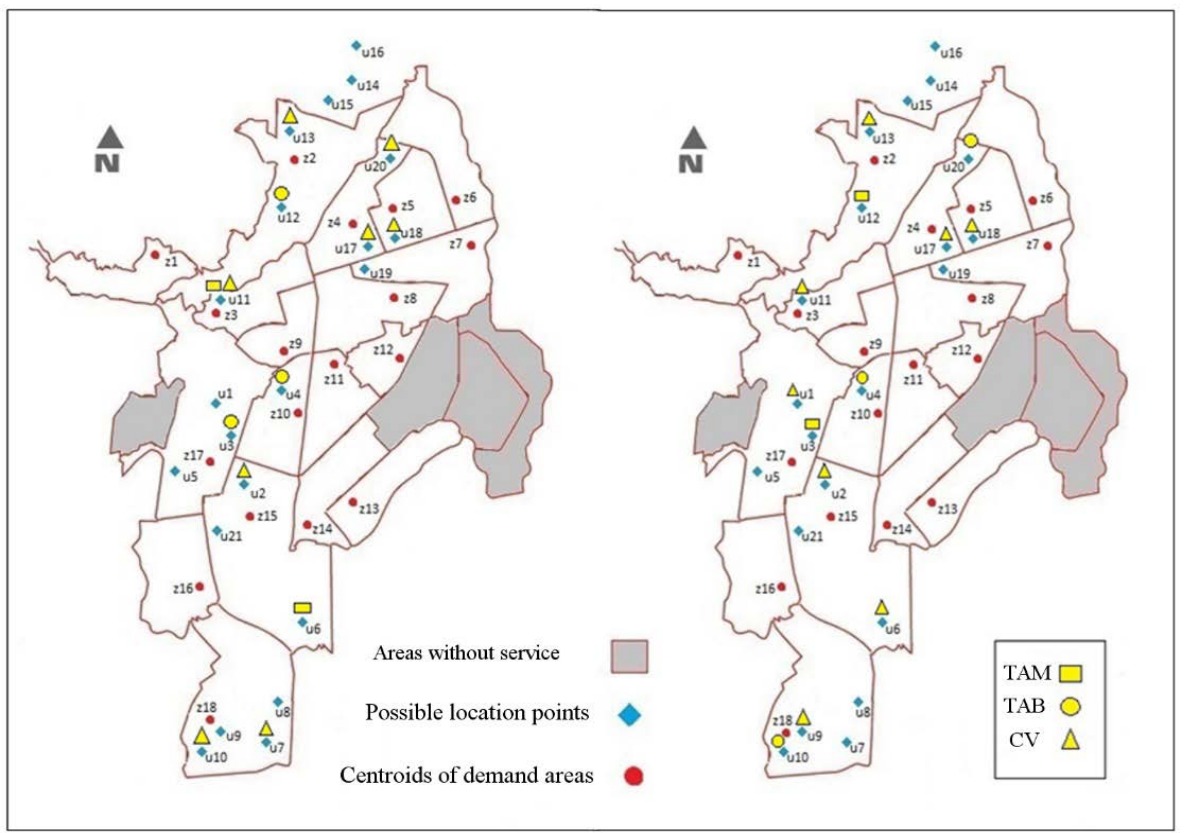

4. The average time of a vehicle between two locations of the city is based on information from Google Maps with some variations incorporated depending on the service type and the time of day. Google Maps information defines the standard travel times (Service type and traffic level are the two factors considered in the variations of the travel times). Two levels of traffic are determined, the first corresponds to a normal level which not significantly alter the standard travel times, the second corresponds to a high level (peak time) which increases travel times. These variations were quantified in factors affecting standard travel times.

5. Demand data were determined using historical data provided by the company, and classified by communes, type of service and period of the day: number expected of calls of each service in each area and in each period of the day (Figure 2).

The maximum number of calls of each service type that can be covered by a vehicle in a period is calculated using the average time of each service, which begins with the displacement of the vehicle to cover the service, and it ends when the service is completed.

\section{RESULTS}

The Table 2 (Table 3) shows the obtained results for Model 1 (Model 2): period (Column 1), the optimum value of the objective function (Column 2), the percentage of demand areas covered with single coverage (Columns 3-5) and with double coverage (Columns 6-8) for each service. The Column 9 shows the number of located vehicles (first number) and available vehicles (second number). The number of vehicles relocated in each period over the previous period is shown in the last column. Service types are denoted as EMG (emergency), URG (urgent) and HV (home visit). The Period 10 is selected in some analysis since it is one of the four periods of the day where the entire fleet is available, and being also the period with a significantly greater level of demand for all services. 
Figure 2. Behavior of the average demand and by type of service and time (upper) and area (lower)

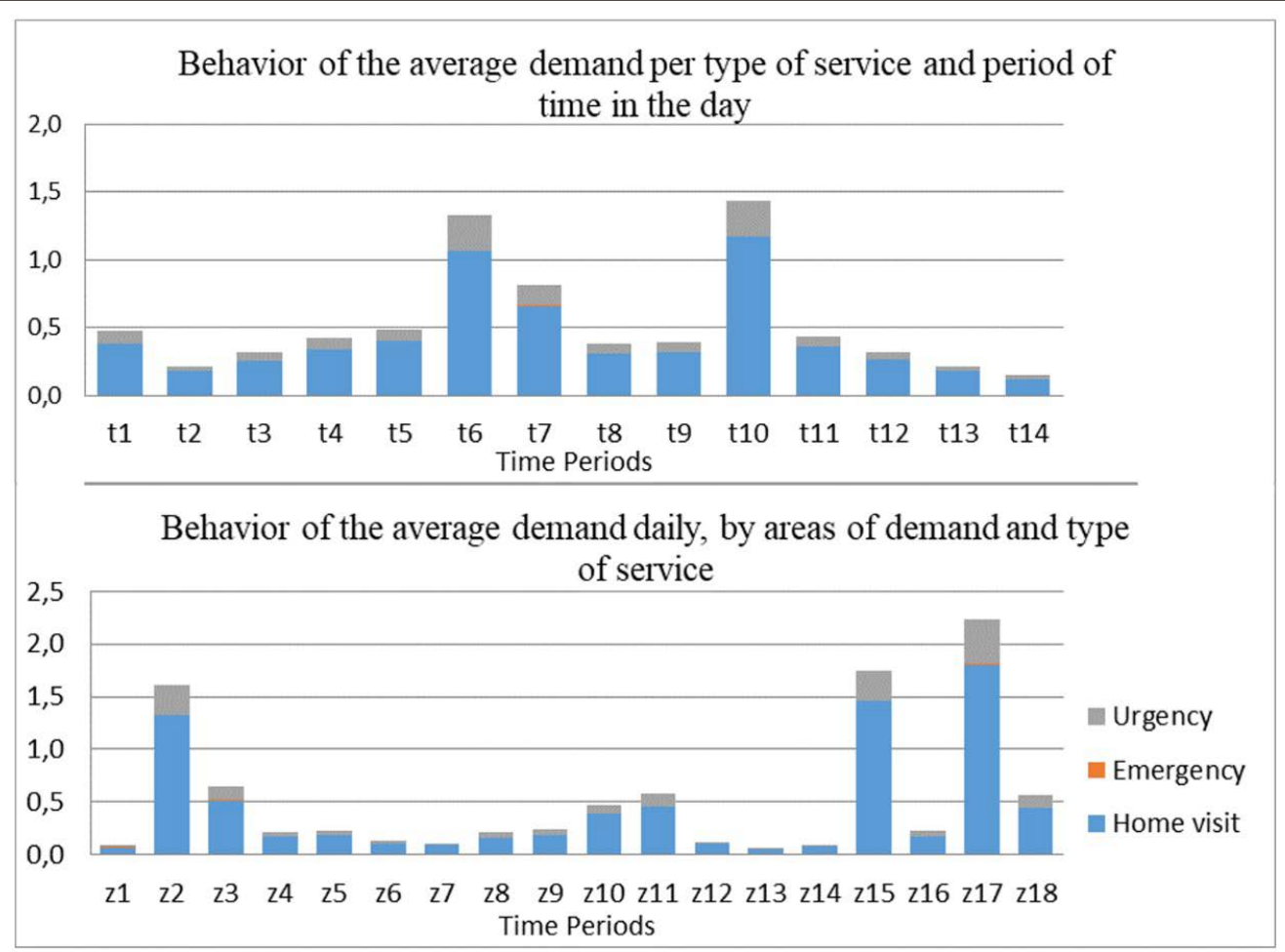

\begin{tabular}{|c|c|c|c|c|c|c|c|c|c|}
\hline \multirow{2}{*}{ Period } & \multirow{2}{*}{ Op. value } & \multicolumn{3}{|c|}{ Simple coverage } & \multicolumn{3}{|c|}{ Double coverage } & \multirow{2}{*}{$\begin{array}{c}\text { Located/Available } \\
\text { vehicles }\end{array}$} & \multirow{2}{*}{$\begin{array}{c}\text { Relocated } \\
\text { vehicles }\end{array}$} \\
\hline & & EMG & URG & HV & EMG & URG & HV & & \\
\hline 1 & 0,614 & 30,0 & 44,4 & 77,8 & 0,0 & 5,6 & 27,8 & $3 / 3$ & 0 \\
\hline 2 & 0,712 & 12,5 & 46,7 & 88,9 & 0,0 & 6,7 & 50,0 & $5 / 5$ & 0 \\
\hline 3 & 0,584 & 0,0 & 11,8 & 72,2 & 0,0 & 0,0 & 44,4 & $8 / 8$ & 3 \\
\hline 4 & 0,762 & 0,0 & 23,5 & 83,3 & 0,0 & 0,0 & 66,7 & $12 / 12$ & 0 \\
\hline 5 & 0,816 & 0,0 & 50,0 & 94,4 & 0,0 & 16,7 & 88,9 & $11 / 13$ & 1 \\
\hline 6 & 0,815 & 40,0 & 44,4 & 94,4 & 0,0 & 16,7 & 88,9 & $13 / 13$ & 1 \\
\hline 7 & 0,825 & 33,3 & 44,4 & 94,4 & 0,0 & 16,7 & 83,3 & $11 / 11$ & 0 \\
\hline 8 & 0,822 & 50,0 & 44,4 & 94,4 & 0,0 & 16,7 & 72,2 & $10 / 10$ & 0 \\
\hline 9 & 0,824 & 20,0 & 44,4 & 94,4 & 0,0 & 16,7 & 83,3 & $11 / 11$ & 0 \\
\hline 10 & 0,777 & 0,0 & 33,3 & 83,3 & 0,0 & 0,0 & 66,7 & $13 / 13$ & 1 \\
\hline 11 & 0,825 & 28,6 & 44,4 & 94,4 & 0,0 & 16,7 & 88,9 & $13 / 13$ & 1 \\
\hline 12 & 0,827 & 50,0 & 47,1 & 94,4 & 0,0 & 5,9 & 88,9 & $10 / 10$ & 0 \\
\hline 13 & 0,789 & 25,0 & 50,0 & 88,9 & 0,0 & 6,3 & 55,6 & $6 / 6$ & 0 \\
\hline 14 & 0,846 & 25,0 & 47,1 & 88,9 & 0,0 & 5,9 & 44,4 & $5 / 5$ & 0 \\
\hline \multicolumn{10}{|c|}{ Source: Author } \\
\hline
\end{tabular}


TABLE 3. RESULTS OF MODEL 2

\begin{tabular}{|c|c|c|c|c|c|c|c|c|c|}
\hline \multirow{2}{*}{ Period } & \multirow{2}{*}{ Op. value } & \multicolumn{3}{|c|}{ Simple coverage } & \multicolumn{3}{|c|}{ Double coverage } & \multirow{2}{*}{$\begin{array}{c}\text { Located/Available } \\
\text { vehicles }\end{array}$} & \multirow{2}{*}{$\begin{array}{c}\text { Relocated } \\
\text { vehicles }\end{array}$} \\
\hline & & EMG & URG & HV & EMG & URG & HV & & \\
\hline 1 & 0,445 & 40,0 & 44,4 & 77,8 & 0,0 & 5,6 & 27,8 & $3 / 3$ & 0 \\
\hline 2 & 0,509 & 12,5 & 46,7 & 88,9 & 0,0 & 6,7 & 50,0 & $5 / 5$ & 0 \\
\hline 3 & 0,489 & 20,0 & 29,4 & 72,2 & 0,0 & 0,0 & 27,8 & $8 / 8$ & 1 \\
\hline 4 & 0,548 & 12,5 & 35,3 & 83,3 & 0,0 & 0,0 & 55,6 & $12 / 12$ & 0 \\
\hline 5 & 0,584 & 66,7 & 55,6 & 94,4 & 0,0 & 5,6 & 83,3 & $12 / 13$ & 0 \\
\hline 6 & 0,581 & 40,0 & 55,6 & 94,4 & 0,0 & 5,6 & 88,9 & $13 / 13$ & 0 \\
\hline 7 & 0,582 & 44,4 & 55,6 & 94,4 & 0,0 & 5,6 & 88,9 & $11 / 11$ & 0 \\
\hline 8 & 0,578 & 100 & 55,6 & 94,4 & 0,0 & 5,6 & 83,3 & $10 / 10$ & 0 \\
\hline 9 & 0,577 & 60,0 & 55,6 & 94,4 & 0,0 & 5,6 & 88,9 & $11 / 11$ & 0 \\
\hline 10 & 0,565 & 9,1 & 38,9 & 83,3 & 0,0 & 0,0 & 61,1 & $13 / 13$ & 0 \\
\hline 11 & 0,586 & 57,1 & 55,6 & 94,4 & 0,0 & 5,6 & 88,9 & $13 / 13$ & 0 \\
\hline 12 & 0,582 & 75,0 & 47,1 & 94,4 & 0,0 & 5,9 & 72,2 & $10 / 10$ & 0 \\
\hline 13 & 0,539 & 75,0 & 56,3 & 88,9 & 0,0 & 6,3 & 44,4 & $6 / 6$ & 1 \\
\hline 14 & 0,529 & 50,0 & 52,9 & 83,3 & 0,0 & 5,9 & 44,4 & $5 / 5$ & 0 \\
\hline
\end{tabular}

Regarding the Model 1: The average time run for each period was 0,02 seconds. The highest value of the objective function is recorded in the Period 14 where coverage is relatively high and vehicles aren't relocated. However, in the Period 12 the coverage is highest, this happen because the demand in Period 14 is higher than in Period 12. In Period 5 two vehicles aren't used due to: the restriction about the number of vehicle of the same type in the same location, and the restriction of compliance times defined by the first coverage radius. Emergencies are generally the services less covered in the first coverage radius, due to the few vehicles that can assist this service type and demanding compliance times. Only in Periods 8 and 12 the percentage of single coverage for emergencies is, in proportion to the areas where this service is demanded, higher than percentages of single coverage for urgencies, because of the few areas where it is expected that an emergency can appear. Home visits have greater coverage within first radius, due to having the highest number of qualified vehicles to attend this service and compliance times greater for coverage within that radius.

Figure 1 shows the geographical location of each vehicle type in the city for the Period 10, according the Models. Also, possible location points and demand areas with their centroids are showed.

Regarding the Model 2: The run time of this model in all the periods is less than 1 second. The objective function differs from Model 1, therefore the optimal values of both models are not comparable. Vehicles are relocated less than in Model 1, due to the absence of the second radius coverage that forcing to cover the total demand within that radius. The solutions of this model show, considering all periods, higher single coverage of emergencies and urgencies than Model 1. The dispersion of vehicles is greater in Model 2, to favor single coverage. This does not mean that the emergency services will be covered in more areas in absolute terms, but in proportion to the areas number in which (at least) one call service is expected. 
Figure 3. Preparedness levels in the Period 10 for home visit service (upper), urgency service (middle), emergency service (lower)

Preparedness levels for home visit service in the Period 10
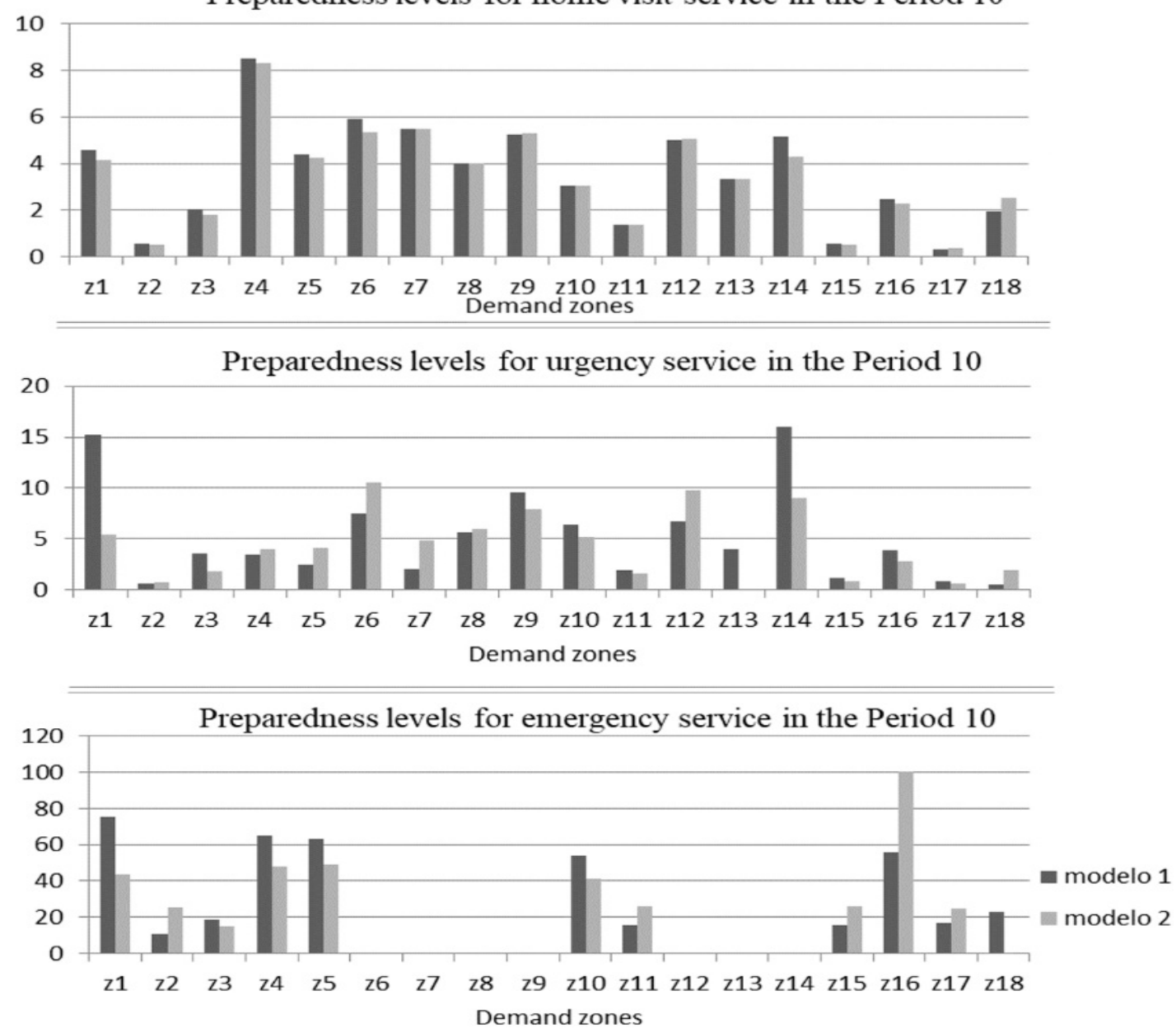

\subsection{Preparedness}

In the context of our work the preparedness of an area $j(j)$ for a service $s(s S)$ is defined as:

$$
h_{j s}=\frac{\omega_{s}}{d_{j s}} \sum_{i \in I_{j s}^{2}} \sum_{k \in K_{s}} \frac{1}{u_{i j s}} y_{i k}
$$

If the demand for a service in an area is high, the level of Preparedness will be disfavored. If the travel time of vehicles located to cover a service type in an area is shorter, the level of Preparedness will be higher.
The definition of Preparedness proposed is used to identify if there are some models better than others, considering maximize the Preparedness, according with the definition proposed in (34), for care areas and types of services, with instances from the case study. The set of locations $i$ that can cover with radius 2 the service type in the zone $j\left(I_{j s}^{2}\right)$ applies just for Model 1, because these have two radius; in the case of Model 2 is replaced for the set of locations that can cover with the only radius considered $\left(I_{j \mathrm{~s}}^{1}\right)$. Figure 3 show the performance of the Preparedness level in each area for each model in the Period 10, 
for the three types of services: Home visit (Upper), Urgency (Middle) and Emergency (Lower).

The cumulative value of preparedness in the Period 10 are 566,7 (Model 1) and 537,5 (Model 2). According to this, Model 1 is the best; however, in the rest of the periods the locations of vehicles change and the levels of preparedness may be different.

The Model 2 has better preparedness level than the Model 1 for Urgencies in 8 areas, for home visits in 9 areas and for emergencies in 6 areas. Levels of Preparedness in emergency services are higher than in the other services, in both models. The lack of expected demand of emergency services, favors the readiness of the system to offer this service. Although the home visits service has a greater number of vehicles available, levels of Preparedness are significantly lower compared to the urgency and emergency services, due to the expected high demand for this service.

\section{CONCLUSIONS AND FUTURE WORK}

Two variants of a model of Integer Linear Programming, are proposed to optimize the ambulance locations of a company of pre-hospital care in the city of Cali, Colombia. The proposed models do not match any of those found in the literature, according to the extensive review made about ambulance location problems and some of its applications to some EMS. The AHP method was the tool selected to determine the appropriate weights for each term in the objective function, based on expert judgment. The validation of the models were made with historical data of the company and some estimates based on external sources. The results show favorable arguments to improve decisionmaking in this process by the company.

A Preparedness function is defined (from a formulation for dispatch of vehicles) to compare the models, as regard to measure the readiness of the system to the expected demand. The results of the models implementation with real data of the company are used. These new results show that the relevance of each model depends of the prioritization of services and/or areas that the company considers. For example, if the priority of the system is the home visit service, according this analysis, the Model 4 is the best fit.

Two other models were developed, versions multi-period of Models 1 and 2, respectively, which didn't are considered in this paper. A future work is the development of a probabilistic variant of the formulated models, which could improve the quality of solutions. The Preparedness definition proposed in this paper could be used to propose a dynamic relocation model; the level of Preparedness could indicate at what moment vehicles should be relocated to maintain quality of the service.

\section{REFERENCES}

ALSALLOUM, O. I. \& RAND, G. K. 2006. Extensions to emergency vehicle location models. Computers \& Operations Research, 33, 2725-2743.

ANDERSSON, T. \& VÄRBRAND, P. 2007. Decision support tools for ambulance dispatch and relocation. Journal of the Operational Research Society, 58, 195-201.

BÉLANGER, V., RUIZ, A. \& SORIANO, P. 2015. Recent advances in emergencymedical services management, Tech. Rep. CIRRELT-2015-28, CIRRELT.

BERALDI, P., BRUNI, M. E. \& CONFORTI, D. 2004. Designing robust emergency medical service via stochastic programming. European Journal of Operational Research, 158, 183-193.

BROTCORNE, L., LAPORTE, G. \& SEMET, F. 2003. Ambulance location and relocation models. European journal of operational research, 147, 451-463.

CÉSPEDES, S., VELASCO, N. \& AMAYA, C. 2009. Localización y relocalización de ambulancias del centro regulador de urgencias y emergencias de Bogotá.

CHURCH, R. \& REVELLE, C. The maximal covering location problem. Papers of the Regional Science Association, 1974. Springer, 101-118.

DASKIN, M. S. 1983. A maximum expected covering location model: formulation, properties and heuristic solution. Transportation science, 17, 48-70.

DASKIN, M. S. 1984. Location, dispatching and routing models for emergency services with stochastic travel times. 
DASKIN, M. S. \& STERN, E. H. 1981. A hierarchical objective set covering model for emergency medical service vehicle deployment. Transportation Science, 15, 137-152.

GENDREAU, M., LAPORTE, G. \& SEMET, F. 1997. Solving an ambulance location model by tabu search. Location science, 5, 75-88.

GOLDBERG, J., DIETRICH, R., CHEN, J. M., MITWASI, M. G., VALENZUELA, T. \& CRISS, E. 1990. Validating and applying a model for locating emergency medical vehicles in Tuczon, AZ. European Journal of Operational Research, 49, 308-324.

GOLDBERG, J. B. 2004. Operations research models for the deployment of emergency services vehicles. EMS management Journal, 1, 20-39.

GRODZEVICH, O. \& ROMANKO, 0. 2006. Normalization and other topics in multi-objective optimization.

HOGAN, K. \& REVELLE, C. 1986. Concepts and applications of backup coverage. Management science, 32, 14341444.

MANDELL, M. B. 1998. Covering models for two-tiered emergency medical services systems. Location Science, 6, 355-368.

ORTEGA, A. E. R., POMAR, L. A. \& PEÑA, J. P. 2007. Diseño metodológico para la ubicación de ambulancias del sector de atención prehospitalaria en bogotá dc 1 . Revista Ingeniería Industrial, 6.

REVELLE, C. \& MARIANOV, V. 1991. A probabilistic FLEET model with individual vehicle reliability requirements. European Journal of Operational Research, 53, 93-105.

SAATY, T. L. 2008. Decision making with the analytic hierarchy process. International journal of services sciences, 1, 83-98.

SCHILliNG, D., ELZINGA, D. J., COHON, J., CHURCH, R. \& REVELLE, C. 1979. The TEAM/FLEET models for simultaneous facility and equipment siting. Transportation Science, 13, 163-175.

SCHMID, V. \& DOERNER, K. F. 2010. Ambulance location and relocation problems with time-dependent travel times. European journal of operational research, 207, 1293-1303.

SINGER, M. \& DONOSO, P. 2008. Assessing an ambulance service with queuing theory. Computers \& operations research, 35, 2549-2560.

SU, Q., LUO, Q. \& HUANG, S. H. 2015. Cost-effective analyses for emergency medical services deployment: A case study in Shanghai. International Journal of Production Economics, 163, 112-123.

TOREGAS, C., SWAIN, R., REVELLE, C. \& BERGMAN, L. 1971. The location of emergency service facilities. Operations Research, 19, 1363-1373.

TORO-DÍAZ, H., MAYORGA, M. E., CHANTA, S. \& MCLAY, L. A. 2013. Joint location and dispatching decisions for emergency medical services. Computers \& Industrial Engineering, 64, 917-928.

VILLEGAS, J. G., CASTAÑEDA, C. \& BLANDÓN, K. A. 2012. Mejoramiento de la localización de ambulancias de atención prehospitalaria en medellín (colombia) con modelos de optimización. CLAIO/SBPO2012, 123,12 .

\section{PARA CITAR ESTE ARTÍCULO TO REFERENCE THIS ARTICLE / PARA CITAR ESTE ARTIGO /}

Zapata-Murillo, P.; Baldoquin. M.G. (2018). Vehicle Location Models for Emergency Medical Services. An Application for a Colombian Company. Revista EIA, 15(29), enero-junio, pp. 31-46. [Online]. Disponible en: https://doi.org/10.24050/ reia.v15i29.1211 